\title{
A política à luz da história em Merleau- Ponty: os primeiros passos
}

\author{
Luiz Damon Moutinho
}

Universidade de São Carlos - UFSCar

\section{RESUMO}

A partir de uma leitura de Humanismo e Terror, busco destacar alguns elementos de uma política em Merleau-Ponty.

\section{PALAVRAS-CHAVE}

História; Política; Violência; Marxismo; Merleau-Ponty.

\section{ABSTRACT}

From a reading of Humanism and Terror, I seek to highlight some elements of a politics in Merleau-Ponty.

\section{KEY WORDS}

History; Politics; Violence; Marxism; MerleauPonty. 
I.

Que política pode vir da fenomenologia de Merleau-Ponty? Dessa filosofia que procura, antes de mais nada, detectar o sentido - e, de início, aquele da orientação no mundo? Que pensa a história em mesma chave, à maneira de uma linguagem? Como pensar, a partir daí o poder, o conflito, a luta? Foucault ironiza esse modelo, preso a signos e significados, e por isso incapaz de dar conta de uma história que é antes, assegura ele, belicosa, sangrenta, marcada por lutas, estratégias e táticas (Foucault, 2001, p. 145). A filosofia do sentido parece demasiado cândida para dar conta do mundo bruto da força.

No entanto, já no prefácio a Humanismo e terror - primeiro livro de MerleauPonty dedicado ao tema -, a política faz entrada pela violência e a história aparece ali, reiteradamente, como luta. É verdade que o tema de abertura é a crítica dos "comunistas" à "violência liberal", retomando uma crítica clássica dos comunistas: o apego liberal aos "princípios" não é apenas, reza a crítica, uma "cobertura" para a violência (do desemprego, da exploração, do colonialismo, da guerra), mas tais "princípios" "formam sistema" com ela, são seu "ponto de honra espiritualista" (Merleau-Ponty, 1946, p. IX) - Merleau-Ponty cita passagem da Crítica da filosofia do direito de Hegel, no momento em que Marx faz a crítica da religiáo, apontando-a como "o suspiro da criatura oprimida, o ânimo de um mundo sem coração, [...] o espírito de estados de coisas embrutecidos" (Marx, 2005, p. 145). Não se trata então, segundo esse modelo, de negar os "princípios" - não se trata de dizer que a religiáo é apenas "aparência" ou "comédia", tal como Voltaire - mas de tomá-los como "parte", como "expressão" desse mundo - "formar sistema" -, como "verdadeiro em seu lugar", como tendo um "sentido" (Merleau-Ponty, 1995, p. 155; 156). Menos que fazer a crítica do liberalismo no nível de suas ideias, portanto, trata-se de reintegrá-las às "relações humanas que o Estado liberal estabelece efetivamente" (Id., 1946, p. X) - da mesma maneira que se trata de tomar a religião como "um fenômeno fundado nas relaçóes inter-humanas" (Id., 1995, p. 155). É então que a pureza dos princípios, menos que absolver o Estado liberal, condena-o - já que tal pureza "não passa na prática” (Id., 1946, p. X): "uma sociedade [...] vale o que valem nela as relaçóes do homem com o homem [...] relaçôes jurídicas, sem dúvida, mas também formas do trabalho, da maneira de amar, de viver e de morrer" (Ibid.). O vocabulário aqui é o do "concreto": diante de um "estudo concreto das sociedades", o liberalismo aparece como "espiritualismo" hipócrita, cujos valores não "passam" na "prática".

Essa passagem ao "concreto" - vale a pergunta - significa uma inversão, uma substituição do plano dos "princípios" - que são, no limite, apenas uma "moral" - por um plano que venha de baixo, por exemplo, a economia? Não se trata disso. Trata-se antes de fazer relevar uma práxis em que "economia e ideologia [estejam] ligadas 
interiormente na totalidade da história" e exprimam um "modo de coexistência dos homens" (Id., 1995, p. 159). Não se trata, portanto, da determinaçấo e anterioridade de um ou outro plano, mas de seu vínculo interno. Isso, por sua vez, vai conformando a história (merleaupontiana, marxista) - a qual vai exigir ainda um outro elemento, que Merleau-Ponty julga também encontrar no jovem Marx: o vínculo com a natureza. Essa práxis é ainda, diz ele, "a maneira pela qual essa sociedade restabeleceu sua relaçáo fundamental com a natureza” (Ibid.). Mas não é ainda esse o tema. Importa aqui, por ora, destacar essa história concreta em que as partes - a moral, o direito, o trabalho etc. "são interiormente ligadas e se exprimem uma à outra" (Ibid., p. 166). Resulta daí que não há nada fora da história, que nada advém a ela senáo pela práxis inter-humana.

\section{II.}

Voltemos à violência. E ressaltemos o reconhecimento da política revolucionária como a política comunista - e que tal política é, "em sua forma, ditatorial e totalitária” (Merleau-Ponty, 1946, p. XIV). A violência não é qualquer uma, mas apenas aquela fundada no proletariado que, por sua situaçáo particular privada do interesse faccioso - pois o proletariado não teria nada de específico a preservar - pode "fundar uma humanidade" (Ibid.). Interessa a Merleau-Ponty investigar se, "no comunismo de hoje", a violência "tem o sentido que tinha [no comunismo] de Lenin", se ele "é igual a suas intenções humanistas" (Ibid.). E, para isso, ele prepara sua "filosofia política", os elementos que permitem avaliar o "problema comunista" (Ibid., p. XIII). São esses elementos que importa aqui destacar.

Assim, ao fim da primeira parte do livro, ele afirma: "até aqui, delimitamos nosso terreno de discussão" (Ibid., p. 104). Apesar das diferenças entre Trotsky, Bukharin, Lenin, Stalin, essas diferenças não são absolutas (Ibid., p. 97; 103); o terreno comum - comum também a Merleau-Ponty - é a ideia de uma história em aberto, que compreende contingência e risco, é a ideia de que, "se há um movimento espontâneo da história objetiva", há também "uma intervenção humana" (Ibid., p. 95), e que mesmo que a revolução esteja "no sentido da história", ela precisa da "iniciativa dos indivíduos" (Ibid., p. 94). Por isso mesmo, ela será uma "revolução forçada", ela será "violência" - e, nesse caso, uma oposição "humanista" pode até "ser contrarrevolucionária" (Ibid., p. 99): há terror na história, diz Merleau-Ponty, "porque há uma contingência” (Ibid., p. 98). Porque a história não segue linha reta, porque os fatos não carregam a evidência de uma única soluçáo possível, as divergências aparecem (Ibid., p. 100). A história não oferece "problema”, ela não pede "soluçôes", ela não é como um problema de geometria em que se lida com uma incógnita: a história oferece uma indeterminaçâo, não há nela, como há na geometria, uma relação já decidida entre os dados e a incógnita (Ibid., p. 203) - ou como se Deus já tivesse fixado o porvir; antes 
disso, a história oferece enigmas (Ibid., p. 101). E é isso que abre as divergências políticas e tornam inevitáveis "a astúcia, a mentira e a violência” (Ibid., p. 103).

III.

Vem daí uma "dialética entre o objetivo e o subjetivo" (Ibid.), ancorada nessa ambiguidade entre a lógica da história e a escolha subjetiva. Ela é a fonte de um dilema a partir do qual Merleau-Ponty pretende compreender os infames "Processos de Moscou" - mais especificamente, o caso de Bukharin, o grande economista e teórico marxista, membro da velha guarda revolucionária bolchevique, que, levado a julgamento em 1938, reconhece em uma "confissão" forçada que sua própria conduta foi marcada por uma "ambiguidade inevitável", o que justificaria, a seus próprios olhos, sua condenação (ele será executado nesse mesmo ano) (Ibid., p. XII). Diferente, na avaliação de Merleau-Ponty, é a situação de Rubachof, personagem de Koestler baseado talvez em Bukharin, pois aí se trata de um caso de "revolta moral" (Koestler, 1940). Ele não suportou a disciplina nova do partido, e sua moral era a da obediência (Merleau-Ponty, 1995, p. XI). Rubachof, como Koestler, vê a história como um "deus insondável” que, nessa medida, ignora o indivíduo, para ele, apenas reflexo, espelho da objetividade (Ibid., p. 16). Ele ignora, assim, a dialética, a "troca entre o subjetivo e o objetivo", que, para MerleauPonty, "é o segredo dos grandes marxistas" (Ibid., p. 25). São ambos, Rubachof e Koestler, "pré-marxistas": "o marxismo não é nem a negação da subjetividade e da atividade humana, nem o materialismo científico de que partiu Rubachof (Ibid., p. 24). Rubachof separa o interior e o exterior, o que o impede de ver a história como uma "lógica viva" (Ibid., p. 17), inseparável da atividade humana - ao contrário, ele a via como um técnico vê um "objeto manipulável” (Ibid.). Daí, para ele, duas grandes concepçóes da moral humana: ou o indivíduo é sagrado (humanismo cristão), ou ele é subordinado à comunidade, aos fins coletivos (Ibid., p. 1617). Porque toma o homem como "engrenagem" e a história como um "relógio" (Ibid., p. 24-25), ele não ultrapassa essa "situação dialética" que se limita a descrever (Ibid., p. 15): a nova política do Partido aparece ao disciplinado Rubachof como "a exigência de que a engrenagem se revolte contra o relógio e mude seu movimento" (Ibid., p. 25) - e, assim, entre a passividade e a revolta, Rubachof escolhe a revolta moral. Daí haver para ele duas alternativas, conforme às duas morais: a do Comissário (que trata os homens como instrumentos) e a do Yogi (que lhes pede uma reforma interior) (Ibid., p. 26). É Bukharin que vai ultrapassar a alternativa da qual Koestler e Rubachof não conseguem sair.

De início, a "vida interior" aparece como uma mistificação para o marxista - tal como para o fenomenólogo. O homem vive no mundo e na história (Ibid., p. 23). A 
relação a si não é a primeira, o egoísmo, o interesse, a solidão são fenômenos segundos. Segue-se que também os atos políticos não devem ser julgados pela moral do agente, a partir dele mesmo, mas "conforme o sentido que eles têm no contexto histórico e na fase dialética em que se produzem" (Ibid., p. 36). A "responsabilidade" se estende a todos os atos, gloriosos e indignos (Ibid., p. 44-45), ela implica não aquilo que os homens quiseram, mas o que descobrem ter feito à luz do acontecimento, e assim, uma "dura ideia de responsabilidade" (Ibid., p. 46). A escolha do colaborador e do resistente, por exemplo, são ambas absolutas, embora "absolutas no relativo", quer dizer, elas são tomadas numa dada situação histórica e, acima delas, nenhum juízo “imparcial” é possível. É para o resistente que o colaborador é um traidor. O colaborador será um traidor apenas depois, conforme o tribunal da história ${ }^{1}$, ele será então um traidor "objetiva ou historicamente no dia em que a resistência [tornar-se] vitoriosa” (Ibid.). Aqui se misturam o objetivo e o subjetivo, as circunstâncias e a vontade, e a responsabilidade torna-se histórica. Bukharin foi declarado traidor e se declarou responsável por atos de traição; e, no entanto, ele se recusa a se reconhecer como traidor (Ibid., p. 49-50). Ele não pode "separar a honestidade pessoal e a responsabilidade histórica", pois seria "recusar o juízo da história" (Ibid., p. 51) e ele responde por atos de traição sem ter querido nenhum deles. O que houve?

Novos atos intervieram a ponto de transformar aquela oposição em "aventura" (Ibid., p. 65). "A iminência da guerra", diz Merleau-Ponty, "ilumina retrospectivamente os anos passados" (Ibid., p. 66). E é então que, ao invés da alternativa de Koestler, entre a consciência moral e a eficácia política, entre o subjetivo e o objetivo, entre o Yogi e o Comissário, transparece uma "relação dialética", uma "contradição fundada em verdade": o mesmo homem, frisa Merleau-Ponty, compreende a um só tempo que ele não pode desaprovar a figura objetiva de suas ações (ele é o que é para os outros no contexto da história) e, entretanto, o motivo de sua ação é inseparável dele mesmo ("o motivo de sua ação permanece o valor do homem tal como ele o sente imediatamente" (Ibid., p. 67; grifos meus)): "o mesmo homem busca se realizar nos dois planos" (Ibid., p. 68). Esse "trágico", que é o da contingência histórica, é constitutivo da ação humana: uma dialética pode transformar as intençóes do homem em seu contrário, e ele não pode nem se suprimir como liberdade, nem contestar o tribunal da história, pois sua ação engaja a todos (Ibid., p. 69). Não haveria o trágico se o sentido da história fosse evidente (para onde vai o capitalismo? Para sua estabilização? Cumpre fazer a NEP ou a coletivização?). Há graus de verossimilhança, mas o que quer que façamos será no risco (Ibid., p. 70).

1 “'A história mundial é um tribunal universal', diz Bukharin”. 
É essa divisão do homem consigo mesmo - não do homem com o mundo, do interior com o exterior, que implica, por sua vez, uma alternativa - que revela o trágico, e é nisso que reside todo o segredo das confissóes de Moscou” (Ibid., p. 71).

\section{IV.}

Merleau-Ponty tem por "pré-marxista” a posição de Koestler (Rubachof): ela remete àquela alternativa entre o subjetivo e o objetivo. Bukharin - como Trotsky e Stalin - são "marxistas": "reconhecem o fato da contingência e do Terror, mas, como marxistas também, admitem que essa violência tem um sentido, que é possível (...) tirar dela um porvir humano" (Merleau-Ponty, 1995, p. 104). É bem esse o caso na atual União Soviética? A violência ali aponta uma "nova história" ou é mais um episódio da "história imutável" (Ibid., p. 105), de que a violência é uma constante?

A violência é uma constante, e ela está encravada na própria origem da história: "o que faz que haja uma história humana é que o homem é um ser que se exterioriza, que tem necessidade dos outros e da natureza para se realizar, que se particulariza tomando posse de certos bens e que, por isso, entra em conflito com os outros homens" (Ibid., p. 110). Por aqui, se poderia pensar que o conflito só aparece no momento da "posse dos bens", por conta da propriedade. Antes disso, porém, a violência aparece a Merleau-Ponty como intrínseca à "intersubjetividade" - o que ainda não acontecia ao "mundo humano" da Fenomenologia da percepção. Aparecia ali uma "coexistência pacífica" (Id., 1996, p. 408) em um "mundo comum", e o "conflito" (Ibid., p. 409) se reduzia ao aparecimento de um "cogito tácito", de um "solipsismo vivido" (Ibid., p. 411) - a saída era então mostrar que são ambos "dois momentos de um único fenômeno" (Ibid., p. 412): o "conflito” é só aparente, mera unilateralidade. Ora, pouco tempo depois, Merleau-Ponty dirá que "a violência é nosso destino (lot) como seres encarnados" (Ibid., p. 118), ou ainda: "no sistema das consciências encarnadas, cada uma só pode afirmar-se reduzindo as outras a objetos" (Ibid., p. 110). Exatamente ali onde aparecia a "coexistência pacífica”, aparece agora a violência; exatamente ali onde se afastava uma consciência absoluta, diante da qual outra consciência é forçosamente objeto, e isso levava entâo Merleau-Ponty a um corpo anônimo, pré-pessoal, capaz de coexistência, agora é ainda um corpo, um "corpo encarnado", mas que parece agora deter prerrogativas de uma consciência, voltando à alternativa do sujeito-objeto. Que aconteceu nesse entretempo? Ao invés de recuar a um cogito, ainda que tácito, Merleau-Ponty faz o inverso: aprofunda a encarnação do corpo e é daí que ele vai tirar não aquele "solipsismo vivido", que não era senão um recuo em direção a um cogito tácito; o movimento agora é inverso, é de uma açáo que estende o eu para o outro (enjambe le moi vers autrui), o que Merleau-Ponty também chama de "intrusão" (intrusion) (Ibid., p. 118). Agora, "cada 
liberdade invade as outras" (Ibid., p. XXXIV; grifo nosso) (empieter: invadir, afetar, imbricar, como se faz no ajuste das telhas de um telhado).

Em um texto de 1945, Em torno do marxismo, posterior à Fenomenologia da percepção, Merleau-Ponty faz uma crítica das "ilusóes kantianas da democracia" (mas que também poderia ser de seu próprio "liberalismo" espontâneo, e de sua geração, de antes da guerra) pela suposição de um "sujeito autônomo" e de que as liberdades não invadem umas as outras: "o otimismo democrático admite que, em um Estado em que os direitos do homem são garantidos, nenhuma liberdade imbrica sobre as outras e a coexistência dos homens como sujeitos autônomos e razoáveis está assegurada. É supor que a violência só aparece na história humana de maneira episódica, que as relaçóes econômicas em particular tendem por si mesmas a realizar a justiça e a harmonia, e enfim que a estrutura do mundo natural e humano é racional" (Id., 1995, p. 124; grifos nossos) $)^{2}$. Eu e outrem náo somos puras consciências, náo nos encontramos jamais como para sis em um face a face. Antes disso, somos engajados no mundo - e agora essa conhecida fórmula quer dizer: aquilo que faço engaja também os outros, afeta-os, dispóe deles, imbrica sobre eles, invade-os. E essa consciência encarnada, por sua vez, é alcançada em seu corpo: não se trata de mero jogo de reflexos, simulacros, fantasmas entre "consciências": "a consciência nada pode sem seu corpo e só pode algo sobre os outros agindo sobre os corpos deles" (Ibid., p. 110). Daí porque a alternativa sujeito-objeto muda inteiramente de sentido: dizer que "no sistema das consciências encarnadas, cada uma só pode afirmar-se reduzindo as outras a objetos" (Ibid., p. 110) implica agora inscrever no corpo do outro a dominação - ou a "violência", como prefere Merleau-Ponty.

\section{V.}

Daí um modelo geral de luta do qual se seguem três efeitos - e daí a passagem à política, cujo alvo será "realizar as condiçóes de existência dos valores" que tiver "escolhido" (Ibid., p. 125). A luta é o elemento básico, de "alcance universal", como diz Lefort a propósito de Maquiavel - e em Merleau-Ponty, luta restrita não só à "vida política”, mas também à "vida privada" (Id., 1946, p. 118), de vez que ela se confunde com a antropogênese. Em Maquiavel, a luta implica três efeitos: ou da luta se engendra um poder acima da Sociedade (principado); ou ela se regula de tal modo que ninguém está submetido a ninguém (liberdade); ou ela é impotente para se reabsorver no seio de uma ordem estável (licença). Merleau-Ponty também aponta três efeitos: primeiro, a subjetividade absoluta de um só (ou de alguns) (Ibid., p. 119) transforma

2 Segundo o minucioso Saint Aubert, essa é a primeira ocorrência do termo empieter na obra de Merleau-Ponty; aquela outra de Humanismo e terror, citada acima, é a segunda (Saint Aubert, 2004, p. 37-38). 
em objetos todas as outras (despotismo) (Ibid., p. 110-11) - e aqui é possível fazer um paralelo com o principado; o segundo efeito é uma variação do primeiro, mas se disfarça em "ditadura da verdade objetiva" - variação porque "uma verdade imposta é (...) instrumento da potência" de alguns (Ibid., p. 111). Merleau-Ponty parece pensar aqui em modelos político-teológicos - "o corpo social inteiro (...) condenado a algum destino providencial (...)" -, mas também em modelos que cumpririam alguma "missão filosófica" (Ibid., p. 119), o que bem poderia ser o modelo soviético, embora em Humanismo e terror ele ainda não conclua por esse diagnóstico. A variação dos efeitos em Merleau-Ponty oscila entre o subjetivo (despotismo) e o objetivo (verdade objetiva). O terceiro efeito ultrapassa a alternativa e coloca a todos em igualdade - o que sugere a alternativa republicana de Maquiavel; no entanto, essa igualdade é apenas "nominal", assegura Merleau-Ponty, e se a violência é colocada fora da lei, ela permanece na "vida efetiva", "sob a forma da colonizaçáo, do emprego e do salário" (Ibid., p. 111): de novo, aqui, a maior parte dos homens aparece como "objeto da história" (Ibid., p. 119); enfim, o liberalismo é uma "pseudo-solução" (Ibid., p. 111). Diferentemente de Maquiavel, para quem o critério de variação parece ser apenas a luta, Merleau-Ponty introduz um novo elemento na disputa: o sujeito. A grade sujeito-objeto orientou a variação dos efeitos, que são apenas "diferentes modalidades [dessa] situação fundamental" (Ibid.) que é a luta.

Daí porque aparece em Merleau-Ponty, mas não em Maquiavel, o objetivo de "destruir a alternativa entre a política subjetiva e a política objetiva" (Ibid., p. 119) e submeter a história a uma condição "considerada como humana entre todas: a condição proletária”, só ela "em posição de realizar a humanidade" (Ibid., p. 120). Maquiavel vê a alternativa republicana dentro do quadro da luta. Merleau-Ponty vai buscar uma condição humana que ultrapasse a luta - muito embora reconheça, pela primeira vez, que a luta se confunde com a antropogênese. Claro que essa "humanidade" não vai sem uma "confiança na espontaneidade da história” - daí a metáfora da revolução análoga à intervenção de um médico no parto (Ibid., p. 121-22) - e sem a ideia da universalidade da condição proletária, que não é meramente abstrata (todo homem pode se conceber como homem e reencontrar todos os outros etc.), mas "real": "só ele é a universalidade que ele pensa, só ele realiza a consciência de si de que os filósofos, na reflexão, traçaram o esboço" (Ibid., p. 124-25). A consciência da individualidade e a de classe são idênticas, no proletariado, porque só ele está em "situação universal", em situação de "dependência universal" que ele "experimenta diretamente (...) em seu trabalho e em seu salário", e por isso mesmo ele "tem a chance, mais que nenhum outro, de senti-la como uma 'alienação' ou uma 'exteriorização", de "retomar sua vida em mãos e criar sua própria sua própria sorte em vez de padecê-la" (Ibid., p. 123). Porque não tem interesse particular, sua 
reivindicação é universal. De um lado, uma situação objetiva e, de outro, uma consciência dessa situação de dependência e alienação. Merleau-Ponty constrói esses argumentos recorrendo ao jovem Marx de $A$ ideologia alemã. É a passagem à consciência de classe que torna necessário o Partido, e, segundo reza a teoria, ele deve desenvolver o que está implicado na prática proletária (Ibid., p. 127). Mas a questão de Merleau-Ponty é saber, cem anos após o Manifesto comunista e trinta anos após a primeira revolução proletária, qual a situação a esse respeito.

\section{VI.}

A condição atrasada da Rússia em 1916 já modifica o equilíbrio entre os fatores subjetivo e objetivo no processo revolucionário: "a consciência estava adiantada em relação à economia e o proletariado tinha que dar-se a economia de sua ideologia" (Merleau-Ponty, 1946, p. 141-42). Ora, mas o marxismo concebe a revolução justamente como "o resultado combinado dos fatores objetivos e fatores subjetivos" (Ibid., p. 145). Daí porque, comparado a esse modelo clássico, na fase presente se "superestima o fator objetivo das bases econômicas e subestima o fator subjetivo da consciência proletária” (Ibid., p. 146). Daí o voluntarismo da revolução; daí ser "possível” mostrar a vida soviética em condição oposta à do "humanismo proletário" (Ibid.). Mas Merleau-Ponty não é categórico nisso; prefere dizer que o quadro atual da vida soviética é comparável a essas figuras ambíguas, que aparecem à vontade no espaço como "mosaico plano ou cubo, segundo a incidência do olhar, sem que os materiais em si mesmos imponham uma das duas significaçôes" (Ibid., p. 147). De todo modo, é certo que os comunistas não podem mais crer na "lógica da história", a "lógica segundo a qual a construção de uma economia socialista, o desenvolvimento da produção, se apoia no crescimento da consciência proletária e, por sua vez, a apoia" (Ibid., p. 151). A história, definitivamente, não tomou essa direção (Ibid., p. 159). Mas segue-se daí que o marxismo está "ultrapassado"? (Ibid.). Merleau-Ponty ainda toma a crítica marxista como uma "aquisição definitiva da consciência política", e o problema então é o de "definir, frente ao comunismo, uma atitude prática de compreensão sem adesão e de livre exame sem denegri-lo" (Ibid., p. 159-60).

No lugar do jovem Marx, não é o velho Hegel que teria razão? (Ibid., p. 162) A "classe universal" de Marx não só reduz o Terror ao mínimo, no processo revolucionário, como ainda deve ultrapassá-lo. O velho Hegel, por sua vez, via nos funcionários do Estado a "classe universal", aqueles que "viam por todos o sentido da história e que realizam a humanidade pela força e pela guerra" (Ibid.). Ao invés de um novo humanismo, não foi apenas um Estado autoritário que a revolução forjou? No final das contas, "a filosofia proletária da história" não seria apenas uma ilusão? Merleau-Ponty se pergunta: "ela é ou não aceita pela história?” (Ibid.). Ele formula esse mesmo 
problema no Em torno do marxismo: se admitimos a lógica e a contingência da história, se admitimos que a probabilidade de um acontecimento, seja ela qual for (por exemplo, que o proletariado tome em suas máos a direçáo da sociedade), pode sempre abortar, entáo pode acontecer que "a lógica e a história se divorciem, de sorte que a história empírica nunca realize aquilo que nos parece ser a lógica da história" (Id., 1995, p. 146). A contingência acarreta a ideia de que a dialética da história possa desviar-se em aventuras, que a história efetiva consista apenas em uma série de diversóes o fascismo, o americanismo etc. (Ibid., p. 147). A história não seria então um discurso com uma sequência determinada, mas como as palavras de um bêbado, em que uma ideia aparece e desaparece sem chegar a sua plena expressão (Ibid.). Ora, se é assim, e se Merleau-Ponty admite que a história não tomou a direção humanista, "por que ainda conceder um sursis a esta filosofia?”. "O declínio do humanismo proletário", responde ele, "não é uma experiência crucial que anule o marxismo inteiro" (Ibid., p. 165). Afinal, o que ainda deve ser preservado do marxismo?

A posição de Merleau-Ponty parece "ambígua" (Ibid., p. 173), e não naquele sentido de uma ambiguidade que ultrapassa a mera alternativa. Aqui, aparentemente, permanecemos na alternativa. Pois, de um lado, ele reconhece que foi abandonada a política revolucionária clássica e, de outro, pretende conservar o marxismo como "o enunciado das condiçóes sem as quais não haverá humanidade no sentido de uma relação recíproca entre os homens, nem racionalidade na história" (Ibid., p. 165). A questáo parece girar em torno disso: constatamos desvios na história, mas o marxismo ainda é a filosofia da história (o marxismo "não é uma filosofia da história, é a filosofia da história" (Ibid.). Se dois, três ou quatro grãos de areia ainda não formam um monte de areia, em um certo momento o monte se forma e náo se pode mais duvidar. De desvio em desvio, vem um momento em que o desvio já não é apenas um desvio; nós simplesmente "entramos em um novo regime da história que já não tem mais em comum com a filosofia proletária de Marx” (Ibid., p. 162-63). Haverá essa "prova histórica" (Ibid., p. 163) que desmentiria finalmente o marxismo? Não, não há "experiência crucial" (Ibid., p. 165). Assim, o filósofo pode reconhecer ao mesmo tempo o desvio e a filosofia da história, o que é uma solução bastante precária. Ora, mas entâo por que conservar a filosofia da história?

Por um instante, o filósofo confessa: é que "renunciar a ela é fazer uma cruz sobre a Razão histórica. Depois disso, não há mais que devaneios ou aventuras" (Ibid., p. 165). O mundo e a nossa existência não seriam mais que "um tumulto insensato" (Ibid., p. 168), uma conversa de bêbado. Eis aí o núcleo duro da dificuldade de Merleau-Ponty, que remete ao quadro teórico da Fenomenologia da percepção. Pois era ali que se mostrava a unidade da experiência e do mundo, unidade que se formava por meio de uma síntese temporal. Se, em um dia de sol, acredito ver de longe uma pedra 
no chão, e que na realidade é uma mancha de sol, não tenho um critério, uma diferença intrínseca que me permita romper a ilusão, e assim já me preparo para sentir a pedra sob meus pés - e é por isso mesmo, pela ausência desse index sui, que sou capaz de iludir-me, da mesma maneira que os homens podem desviar-se do curso da história: "a história", diz ele, "não torna impossível nenhuma aventura" (Ibid., p. 166). Ao termo de um movimento de exploração, contudo, a ilusão será barrada - lá e cá. Quer dizer, a própria abertura ao mundo é condição da verdade perceptiva; a verdade não é intrínseca a cada momento, a cada consciência; ela só aparece pela ligaçáo concordante da experiência consigo mesma (Id., 1996, p. 343-44) - da mesma maneira, a história "como que por uma seleçáo natural, elimina no longo prazo (à la longue) aquelas [aventuras] que se desviam (qui font diversion) de sua relação com as exigências permanentes dos homens" (Id., 1946, p. 166). A história, portanto, deve igualmente "barrar" o desvio e retomar seu leito. Mas só a história pode fazê-lo; enquanto estou na "diversão", ainda não sei toda a verdade; é preciso esperar... O attentisme de Merleau-Ponty é, portanto, consequência da doutrina.

Mas, se o attentisme deriva da doutrina, nem por isso ele é uma boa solução. Ele implica um risco, muito bem apontado por $\mathrm{Neves}^{3}$, e esse risco vai exigir uma reformulação da doutrina no seu núcleo duro, ali onde se projeta o universal: na teoria do proletariado, o coração da teoria marxista (121).

\section{Referências bibliográficas}

Foucault, M. (2001). Dits et écrits. Vol. II. Paris: Quarto Gallimard.

Koestler, A. (1940). Darkness at Noon. Londres: Macmillan.

Lefort, C. (1978). Sur une colonne absente. Paris: Gallimard.

Marx, K. (2005). Crítica da filosofia do direito de Hegel. São Paulo: Boitempo.

Merleau-Ponty, M. (1946). Humanisme et terreur. Paris: Gallimard.

(1996). Phénoménologie de la perception. Paris: Gallimard.

(1995). Sens et non-sens. Paris: Galimard.

Neves, J. L. B. (2016), "Merleau-Ponty e o marxismo: política e filosofia da história”, Revista DoisPontos, v. 13, n. 1.

Saint Aubert, E. (2004). Du lien des êtres aux éléments de l'être. Paris: Vrin.

3 "O conceito de diversões da história é um álibi seguro para o dogmatismo: segue-se postulando uma teoria geral, (...) e lamenta-se repetidamente que a empiria náo confirme ainda sua existência de fato, comemorandose simultaneamente que ela não negue sua validade de direito. Ora, é essa separação entre fato e direito que conduz a crítica marxista rapidamente ao idealismo" (Neves, 2016, p. 118). Cf. ainda Lefort, 1978, p. 93. 